Original Research Article

\title{
An Analysis of Spoken English Errors of Tibetan-English Major Students-Take Qinghai Nationalities University for example
}

\author{
Fuchun Zhao \\ Qinghai Nationalities University, Xining City 810007, Qinghai Province, China
}

\begin{abstract}
In order to improve Tibetan-English major students' spoken English, the analysis of oral English errors is essential. Although English majors have more time and more methods to learn English, like other English learners, they will inevitably make mistakes. But what are the common Spoken English errors made by students in the Tibetan-English class in Qinghai Nationalities University? Are the mistakes they make in spoken English the same as those made by students whose mother tongue is Chinese? Mother tongue affects second language acquisition in a large extent. This research aims to find the main types of grammatical errors committed by Tibetan-English major students in spoken English, and through the language developments and changes of freshmen, sophomore and junior students, give relevant correction strategies and provides teachers with corresponding teaching methods. The main tools used in this research are Xunfei recording tools, Xunfei recording to text tools, Excel chart calculation, Word charts and manual counting. The interview method and the random sampling method are mainly used.
\end{abstract}

Keywords: Grammatical Error Analysis; Spoken English; Tibetan students

\section{Introduction}

This chapter will introduce the research background of this thesis, then the porpose of this paper,and finally following the significance of this study.

Since the implementation of China's reform and opening up policy, English has played an important role in international communication. English is the most widely used language in the whole world, and the purpose of learning a language is to communicate. The purpose of learning a foreign language is to be able to use it rather than study it. (Jia Yonghua, 2000) It is necessary to improve spoken English so that to exchange ideas well. Improving spoken English, you must know the mistakes you make in spoken English. Some people started to research English writing errors very early, but there are few studies on spoken errors, because the materials of spoken errors are not easy to collect, and it has brought great research challenges. But the development of science and technology has brought us great convenience in establish spoken corpus. However, most of the previous studies focused on spoken errors of Han English learners, and most of them used existing corpora for analysis. Tibetans are one of our national minorities in China. Their oral English are influenced both by their first language Tibetan and the second language Chinese. The common errors in spoken English are in some ways different from those made by Han students.

Tibetans have their own unique languages, words, cultures, and Tibetan children learn Chinese at a very young age. English is their third language. The pronunciation of Tibetan has a great influence on the pronunciation of English. Tibetan children's ability of learning English is also different from Han children. The purpose of this paper is to find the common grammatical errors of Tibetan-English major students by analyzing their oral English errors, and give corresponding reasonable correction strategies. It is hoped that this results can provide some advice for Tibetan-English students and teachers in their learning and teaching.

It is of great help to improve the quality of teaching if teachers learn the types of students' mistakes. At present, many studies mainly focus on the analysis of spoken English errors of Han students, but there are very few analysis of Tibetan students' English errors, and most of the research on spoken errors is based on the existing corpus, such as oral test corpus, TEM4 and TEM8 oral test Corpus, audio of spoken homework sent by students, etc. This research aims to use the form of interviews, which let students talk about a topic, and use recording software to record students' speeches. On the other hand, this research will list the spoken grammatical errors of students when they speak, and pay attention to different grades Tibetan students' error ratio, in order to clarify their language development. At the same time, the teacher will be given reasonable errors correction strategies to help the teacher's teaching and at the same time to help the students' oral English learning.

\section{Research methodology}

This chapter will introduce the research methodology of this study. The research subjects, research instruments and research

Copyright (C) 2020 Fuchun Zhao

doi: 10.18282/1-e.v9i2.1394

This is an open-access article distributed under the terms of the Creative Commons Attribution Non-Commercial License

(http://creativecommons.org/licenses/by-nc/4.0/), which permits unrestricted non-commercial use, distribution, and reproduction in any medium, provided the original work is properly cited. 
procedures will be presented. Because the Tibetan-English major students are special, I collected the corpus by myself and built a small corpus.

After setting the research goals, I randomly selected 30 Tibetan-English major students, 10 freshmen, 10 sophomores and 10 juniors. They are the students of Qinghai Nationalities University. The interview time for each student was about 10 to 15 minutes, and a small oral English corpus was established. The basic situation of the students is as follows: The survey subjects are students from the three grades of Tibetan-English Normal classes of the 17th to 19th grades of the School of Foreign Languages, Qinghai Nationalities University. Most of their students only started to learn English formally since college, because English doesn't attend their important tests, such as college entrance examination.

Three main instruments are employed in this research, one is the oral topics which are designed for the students, one is recording device. Last but not least, it is the software for doing statistical analysis.

(1) The oral topics

Three topics are designed for the Tibetan-English major students. My research purpose is to figure out their grammatical errors, so I choose these topics to assist my research purpose. The students I surveyed do not have a high level in English. Some of them started to learn English from high school and some started to learn English from junior high school. However, they did not try their best in junior high school or in high school because English did not participate the high school and college entrance exams. To be precise, they only started to study in the real sense at the university. So topic are "my favorite person", "An interesting experience" and "Please describe your classes".

(2) Recording device

I collected the corpus in the form of interviews and ensured one to one interview in a quiet environment, so the recording tool was able to record all the words spoken by the interviewee. When they were talking, their whole words will be recorded. The recording tool is Xunfei Heard, it can grasp people's voice, reduce noise and translate the sentences into corresponding languages.

(3) The software for statistical analysis

Microsoft Excel and Microsoft Word will be used to calculate the proportions of each types of errors.

There are mainly three steps in collecting the oral materials. The first step is to determine the research subjects and the form of collecting materials. The second step is to interview the students, and the last step is to organize materials and analyze it.

(4) When determining the research subjects, if only look for students in a certain grade, the types of grammatical errors may not be complete, and the results are not convincing. So I randomly selected 10 students from each of the three grade so as to be representative. Considering the students' English learning background, when choosing the talk topics, I chose relatively simple topics that are easy to organize language. When deciding to take the form of a corpus, I take the form of interview, and in this form I can record the materials clearly.

(5) The second step is to intereview the students. I prepared 9 notes in advance, and wrote three topics in advance, and make sure the probability of each topic's extraction is the same. Each interviewee enters the classroom separately, ensuring that there are only one interviewee and one interviewer in the classroom, which is helpful to reduce the pressure of interviewees, and at the same time it is convenient to record their voice. The interviewer allows the interviewees to randomly select one piece of paper, and then give him a piece of white paper and a pen,two minutes will be given to them to draft and organize the language, after starting to talk, they need to hand the draft paper to the interviewer, and then start talking about the topic. Of course, during the interview, the interviewee sometimes will be silent, talk not in the target language, or the length of the talking time is not enough. The interviewer needs to continue to ask questions and guide the interviewee to continue to speak. But interviewer can't correct their grammatical errors, the interviewer can only repeat their words and ask questions.

(6) The last step is to organize materials and analyze the recording materials. First, the researcher must listen the materials, and try best to write all the words down. Then with the help of some native speakers and electronic software to analysis it.

\section{Results and discussions}

In this part, the results and the discussions of this research will be presented, and there are mainly two parts, one is different types of grammatical errors of Tibatan English majors in spoken English will be displayed, and some analysis about their language development will be presented and then some error correction strategies will be given. In this research, I choose three grades of Tibetan-English major students in Qinghai Nationalities University, obviously, their English level are different, so I discuss them separately, and some comparision will be made after the analysis of each grade. Regarding the calculation of the grammatical error rate, I first used the Xunfei tool to convert the speech into English text. Because Xunfei can only transform part of the standard English speech, so I listened to the audio repeatedly and tried best to record every meaningful sentence the student said. When analyzing errors, I strictly follow the international English grammar standard, find out the students' grammatical errors and classify them. When calculating the error rate and the frequency of errors made by students, a complete subject-predicate-object structure and a meaningful sentence is taken as a basic unit. If an error occurs in a basic unit, 1 is recorded, and the total number is the basic unit which contained error and the basic unit which doesn't has such error,of course, the premise must be the same grammatical type. The three types of errors are as follows: first, the omission of Be verb, in this type of error, I mainly choose the sentences that are concerned with people, such as described a person's characters or anything else about that person. Second, errors in the number of nouns, in this type of error, I choose the circumstance that students whose spoken English involves the situation that need to use plural form, but they use singular form. Third, error in tense: in this type of error, I consider the situation that when the Tibetan-English major students describe something that happened in the past, they use the simple present tense to describe it.

\subsection{Freshman Tibetan-English major students' main grammatical errors}

According to Zhang (2002), Grammar is to study the morphological changes and the sentence structure. Grammar is "that 
part of a language which can be described in terms of generalization or rules" while lexis appertains to "all the particular facts about language...those which cannot be generalized into rules" (Leech, 1981: 179) Morphological changes includes tense, number of nouns and voice of verbs, and sentence structure mainly analysis word order, sentence elements etc. I had mentioned that the Tibetan-English major students I chose were started learning English formally until they went to university, and their English foundation is not good, so the probability of making grammatical errors is relatively high. When analyzing the grammatical errors of the freshman, I selected three types of grammatical errors which are frequently ignored by them. There are four main types of grammatical errors that are usually made by freshman Tibetan-English major students:

\subsubsection{The omission of be verb}

(1) My grandmother 71 years old, and my grandfather 70 years old.

Correct sentence: My grandmother is 71 years old, and my grandfather is 70 years old.

(2) Many of the students Tibatans.

Correct sentence: Many of the students are Tibetans.

(3) He very kind.

Correct sentence: He is very kind.

After I analysis all these texts, I find that nearly all this kind of error happened when when they talk about people. So when I analysis the rate and the frencency of this error, I mainly choose the sentences that are concerned with people,such as described a person's characters or anything else about that person. Sometimes they made these errors but sometimes they can correct it and said correct sentences. Of course, not all the students made such kind of error, because of different cognitive abilities, they may use different sentences. After my analysis, the rate and the frequency of the error is as follows:

$$
\frac{1+1+4+1+7+2+5+0+1+1}{11+5+8+4+16+5+9+1+7+4}=\frac{23}{70} \approx 0.33
$$

\subsubsection{Errors in the number of nouns}

(1) I have two sister.

Correct sentence: I have two sisters.

(2) There are many dog.

Correct sentence: There are many dogs.

(3) We could play game, sing song.

Correct sentence: We could play games, sing songs

From the materials I collected, I find that when these students meet the circomstances that they need to use the plural form, they use the singular form. I chose this kind of error to analysis. These students whose spoken English involves the situation that need to use plural form, almost all of them use singular form. The rate and the frequency of this kind of error is as follows:

$\frac{3+4+2+1+3+1+0+1+0+0}{3+7+2+2+3+2+3+1+0+2}=\frac{15}{25}=0.60$

\subsubsection{Errors in tense}

(1) Maybe they are not afraid.

Correct sentence: Maybe they were not afraid.

(2) The weather is very good there.

Correct sentence: The weather was very good there.

(3) She is hurt, nobody help her.

Correct sentence: She was hurt, nobody helped her.

These examples show that when the Tibetan-English major students describe something that happened in the past, they always use the simple present tense to describe. So I chose this kind of error, when they say their past time experiences or something that happened in the past, they use the simple present tense rather than the past tense. The rate and the frequency of this kind of grammatical error is as follows:

$$
\frac{3+1+9+1+7+4+3+2+1+2}{4+2+13+3+14+4+4+2+1+2}=\frac{33}{49} \approx 0.67
$$

\subsection{Sophomore Tibetan-English major students' main grammatical errors}

After a year's professional study, the English level of the students should be improved. And does these three types of grammatical errors' rate changed? Of course, these three types of errors are as same as the three types that I mentioned in analyzing freshman students' errors. I need to carefully analyze their spoken English materials and draw conclusions.

\subsubsection{The omission of be verb}

(1) Their grammar and pronunciation all very good.

Correct sentence: Their grammar and pronunciation are all very good.

(2) He not from Qinghai.

Correct sentence: He is not from Qinghai.

(3) I always make fun of him.

Correct sentence: I am always make fun of him.

$$
\frac{1+1+2+0+1+2+2+2+1+0}{7+4+15+7+4+10+12+10+6+8}=\frac{14}{83} \approx 0.17
$$




\subsubsection{Errors in the number of nouns}

(1) I have two sister and one brother.

Correct sentence: I have two sisters and one brother.

(2) I will ask help for my roommate.

Correct sentence: I will ask help for my roommates.

(3) And cherish your friend and your relative.

Correct sentence: And cherish your friends and your relatives.

$$
\frac{3+4+4+3+2+3+3+1+3+2}{7+4+8+12+3+7+12+2+7+5}=\frac{28}{67} \approx 0.42
$$

\subsubsection{Errors in tense}

(1) I visit some beautiful places.

Correct sentence: I visited some beautiful places.

(2) Originally, we don't know each other.

Correct sentence: Originally, we didn't know each other.

(3) When I went home, I sleep with her.

Correct sentence: When I went home, I slept with her.

$$
\frac{11+4+8+7+4+1+2+4+5+4}{15+6+15+15+9+1+6+5+7+6}=\frac{50}{85} \approx 0.59
$$

\subsection{Junior Tibetan-English major students' main grammatical errors}

We can see that sophomore students is lower than freshman students in the rate of these three types of grammatical errors, and some students do not make mistakes in the first type of error. The situation of juniors is as follows:

\subsubsection{The omission of be verb}

(1) He not tall and not short.

Correct sentence: He is not tall and not short.

(2) Most of them from Qinggai province.

Correct sentence: Most of them are from Qinghai province.

(3) When he Grade 3 in middle school.

Correct sentence: When he was in Grade 3 in middle school.

$$
\frac{0+0+0+2+5+3+1+3+2+1}{7+3+10+5+29+19+7+7+9+10}=\frac{17}{106} \approx 0.16
$$

\subsubsection{Errors in the number of nouns}

(1) I followed my neighborhood three day.

Correct sentence: I followed my neighborhood three days.

(2) But some day passed.

Correct sentence: But some days passed.

(3) So I have a number of books to read and vocabulary to memorize.

Correct sentence: So I have a number of books to read and vocabularies to memorize.

$$
\frac{1+1+2+3+1+5+2+0+1+2}{5+5+6+10+9+7+5+5+5+6}=\frac{18}{63} \approx 0.29
$$

\subsubsection{Errors in tense}

(1) So when I am in middle school, my dream is to learn English.

$$
\frac{5+2+6+2+9+43+5+1+1+2}{7+2+12+3+13+76+7+2+2+6}=\frac{76}{130} \approx 0.58
$$

Correct sentence: So when I was in middle school, my dream is to learn English.

(2) Because he graduate from Qinghai university.

Correct sentence: Because he graduated from Qinghai university.

(3) He get married when I was in the middle school.

Correct sentence: He got married when I was in the middle school.

\subsection{Discussions of the results and correction strategies}

Through these datas, we can understand that the error rates of these three types of grammars are gradually decreasing, but the error rates of the second and the third grammar errors are still relatively high. And the results can be seen as follows:

The chart has well illustrates that the error rate is gradually decreasing, but the second and the third type of grammatical error's rate are still very high, so teachers should pay more attention to these two types of grammatical errors when guiding students. And for how to correct students' mistakes, below I will give some error correction strategies. First of all, it is necessary to clearly distinguish the types of errors. Is it an error caused by objective factors such as students' tension and classroom environment, or 
Three types of Grammatical Erros and their ratios

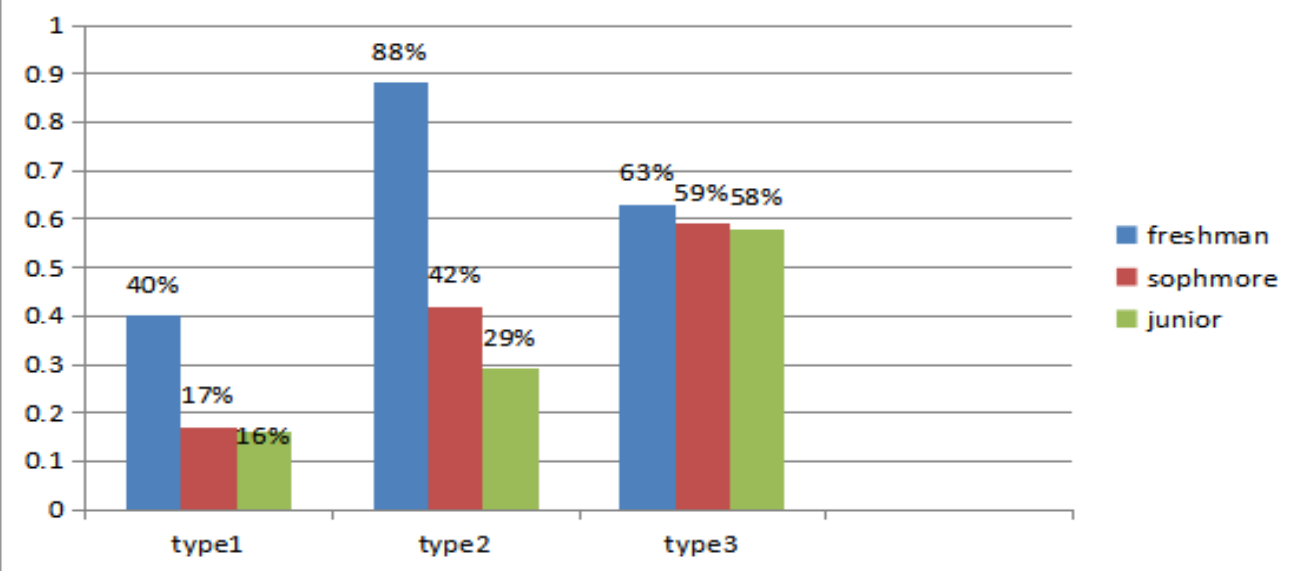

students just speak so fast that make a mistake, or the student has not mastered the knowledge points. Second, the teacher can use the methods like find errors by students themselves or described by the teacher himself when correcting tense or singular and plural errors. These two ways can be conducive in protecting students' self-esteem and improving students' English level. Third, treat synchronic errors and special errors differently. If most of the students in a class have such problems, the teacher can directly correct them in the class time and give the correct answer. But if the errors are made by individual students, the teacher can explain it in private.

\section{Conclusion}

This research focuses on students' oral errors. The error rate of students' spoken English is higher than written, because the form of interviews has higher requirements for language learners, that is why in the same period of time the sophomores' effective text are more than freshman students, and the effective texts of junior students' are more than sophomores. English is the third language of Tibetan students and their learning can be influenced both by Tibetan and Chinese. The mistakes they make are different from Han students. For example, the omission of the Be verb. This type of error is relatively rare among Han students, but Tibetan and other Han students are also prone to make mistakes in tense and singular and plural. When I study their grammatical errors, I choose three types of grammatical errors with relatively high error rates, and these three types of errors are also more representative. But after analyzing the data, I found that in their learning process, these three types of grammatical errors can be slowly reduced, and some students in the upper grades can be completely avoided.

During the interview, I found that Tibetan students basically only started to have formal contact with English until they were freshmen in college, and some students can't speak Chinese fluently. When talking in English, many students ask me if he can speak in Chinese? This is related to their English learning habits. When speak English, they will use Tibetan and Chinese as interlanguage. Therefore, the grammars of Chinese and Tibetan have a great influence on their learning of English.

The shortcomings of this study are mainly that many variables cannot be controlled, so the results of this research are not completely accurate, I can't control the conditions like the content of the students' speech and the length of the effective text recorded by the students. In the research, I also found many other types of grammatical errors, but they cannot be completely listed. This is also the deficiency of this research. Due to the specificness of the speech materials, the analysis relies more on humans, and cannot be used for electronic tools which have higher accuracy. So few suggestions for future researchers are as follows. First, the researchers can compare the spoken materials with Tibetan, and find the negative transfer of mother tongue in the spoken language. Second, I found in this research that Tibetan students' spoken speech is generally more standard than Han students'. Researchers can explore Tibetan students' spoken phonetic errors and understand the differences between Tibetan and Han students' spoken speech. Third, few researchers have discussed the teaching strategies of third language learning and teaching, and it have great significance for minority students to learn a third language, and now third language teachers are also very scarce. Fourth, I only discussed three types of grammatical errors in this paper. Tibetan students also have many problems in spoken English such as the third person singular, English words order, part of speech, etc.

\section{References}

1. Leech, G. Principles of Pragmatics [M]. London: Longman, 1983.

2. Jia Yonghua, Negative Effects of Standardized Foreign Language Testing on Developing Foreign Language Communication Ability [J]. ZhongGong Shang Xi Sheng DangWeiXiaoXueBao, 2000: (3): 63-64.

3. Zhang Daozhen, (2002). Practical English Grammar [M]. Beijing: Foreign Language Education and Research Press. 